\title{
HOMENAJE A CLAUDIA BRIONES
}

HOMAGE TO CLAUDIA BRIONES

HOMENAGEM A CLAUDIA BRIONES

por Ana Margarita Ramos

Doutora em Antropologia Social

aramosam@gmail.com

Universidad Nacional de Rio Negro, Argentina

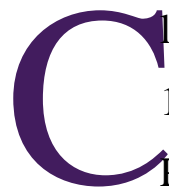
laudia Briones inició su trabajo en 1980, entre los nivaclé del Chaco Paraguayo y las comunidadesmapuche del Neuquén (Argentina). Este último pueblo ha sido el que ha concitado su producción etnológica más sostenida en cuestiones de creencias y patrones cognitivos, ciclo económico y ritual, prácticas matrimoniales y organización social, enculturación, memoria. Progresivamente, la labor ha ido virando hacia el examen de las identidades $y$ relaciones interétnicas, enfatizando el estudio de los procesos organizativos y las producciones y políticas culturales de organizaciones con filosofía y liderazgo mapuche en Neuquén y Río Negro, desde enfoques que han dado especial cabida a las performances y estándares metaculturales involucrados.

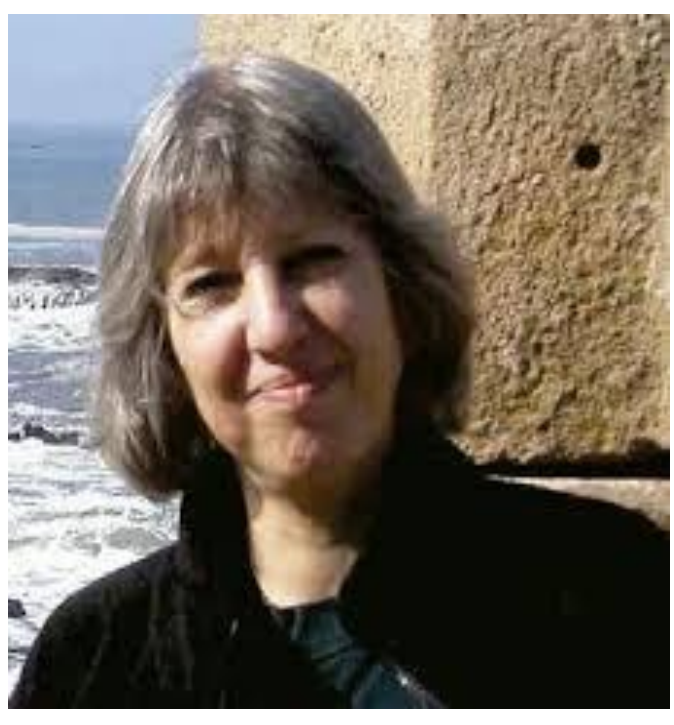

Homenageada

Claudia Noemí Briones

Doctora en Antropología cbriones@unrn.edu.ar; brionesc@gmail.com Universidad Nacional de Rio Negro, Argentina 
A partir de este campo, sostuvo que el examen de las luchas por el reconocimiento de los derechos indígenas y de las políticas estatales indigenistas e interculturales debía enmarcarse en el de las formaciones nacionales y provinciales de alteridad, tratando de ver cómo la neoliberalización de las culturas impacta en Argentina sobre construcciones sedimentadas de aboriginalidad. También ha trabajado sobre los procesos de formación de grupo en base a la articulación de prácticas de Memoria, Parentesco y Política. Recientemente, su interés en prácticas de ampliación y disputa de espacios públicos y nociones de ciudadanía la ha llevado a analizar procesos de politización de la cultura y la culturización de la política. Su trabajo continuo con comunidades y organizaciones mapuche de Neuquén, Río Negro y Chubut ha sido la fuente principal de sus reflexiones antropológicas.

Ha sido Profesora desde 1986 hasta 2008 de la cátedra Sistemas Socioculturales de América I (Cazadores-recolectores y agricultores incipientes), en la Facultad de Filosofía y Letras, Universidad de Buenos Aires. Desde 1996 hasta el presente ha enseñado diversos seminarios de grado $\mathrm{y}$ postgrado en Ciencias Antropológicas en instituciones nacionales y extranjeras. En el año 2008 se muda a la ciudad de San Carlos de Bariloche para crear una carrera de Ciencias Antropológicas en la provincia de Río Negro, donde se desempeña como Coordinadora de la Licenciatura en Ciencias Antropológicas (2008-2010) y como Directora de la Escuela de Docencia de Grado y Posgrado en Humanidades y Estudios Sociales (2009-2011). Actualmente sigue siendo Profesora en esta universidad.

Empezó su trayectoria como investigadora con una Beca de Iniciación (1983-1985) del Consejo Nacional de Investigaciones Científicas y Tecnológicas (CONICET) con un proyecto titulado "El proceso enculturativo entre los mapuche argentinos" y una Beca de Perfeccionamiento (1983-1985) de la Universidad de Buenos Aires con el proyecto "La construcción de la identidad étnica entre los mapuche argentinos". Entre 1991-1994 recibió una beca Fulbright para realizar el doctorado en la Universidad de Texas, en Austin, Estados Unidos. Durante el periodo 1994-1996 obtuvo dos destacadas fellowships para finalizar su doctorado: uno de ellos otorgado por Social Science Research Council y el otro por Wenner-Gren Foundation. En 1994 ingresa 
a la Carrera de Investigación del CONICET, donde actualmente tiene el cargo de Investigadora Principal, el cual desarrolla en el Instituto de Investigaciones en Diversidad Cultural y Procesos de Cambio (IIDyPCA).

Fue profesora invitada en numerosas universidades extranjeras y su prolífera obra ha sido publicada en libros y revistas especializadas en distintos idiomas. $\mathrm{El}$ compromiso de Claudia Briones con la Antropología se ha visto reflejado en los grupos de investigación que ha dirigido a lo largo de todos estos años y en la gran cantidad de colegas que se han formado con ella. Sus teorías sobre los procesos de inclusión y exclusión de los pueblos indígenas al Estado Nación -abordados desde las luchas indígenas por la ampliación de sus derechos, las políticas estatales indigenistas e interculturales, las formaciones de alteridad y las trayectorias mapuche de formación de grupoconstituyen, hoy en día, una escuela de pensamiento insoslayable en el campo de los Estudios Étnicos.

A lo largo de su recorrido intelectual, Claudia Briones se ha detenido a reflexionar acerca de los procesos de recuerdo y olvido en ciertos momentos puntuales, y, en cada una de esas detenciones, incorporó a la discusión antropológica nuevas preguntas y novedosos enfoques acerca de las prácticas sociales de interpolar pasados, presentes y futuros. Sus reflexiones sobre la memoria fueron centrales para pensar la especificidad que adquiere los recuerdos en grupos que han sido subordinados $\mathrm{y}$ alterizados. 